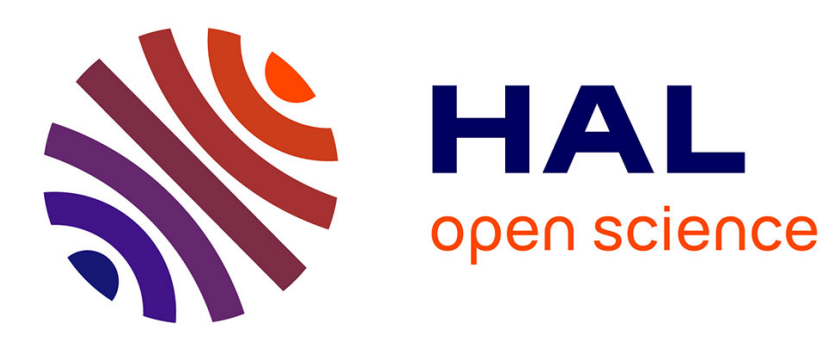

\title{
Estimation of the constitutive law by dual Small Punch Test and Instrumented Indentation
}

\author{
Gildas Guillemot, Adrien van Gorp, Thierry Coorevits, Alain Iost
}

\section{To cite this version:}

Gildas Guillemot, Adrien van Gorp, Thierry Coorevits, Alain Iost. Estimation of the constitutive law by dual Small Punch Test and Instrumented Indentation. Solid State Phenomena, 2012, 188 (Advanced Materials and Structures IV), pp.193-198. 10.4028/www.scientific.net/SSP.188.193 . hal-01170934

\section{HAL Id: hal-01170934 \\ https://hal.science/hal-01170934}

Submitted on 2 Jul 2015

HAL is a multi-disciplinary open access archive for the deposit and dissemination of scientific research documents, whether they are published or not. The documents may come from teaching and research institutions in France or abroad, or from public or private research centers.
L'archive ouverte pluridisciplinaire HAL, est destinée au dépôt et à la diffusion de documents scientifiques de niveau recherche, publiés ou non, émanant des établissements d'enseignement et de recherche français ou étrangers, des laboratoires publics ou privés. 


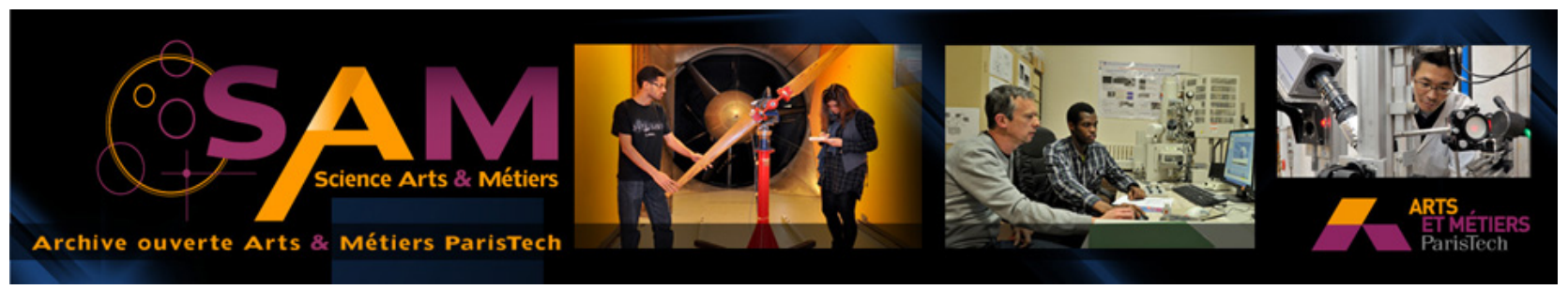

\section{Science Arts \& Métiers (SAM)}

is an open access repository that collects the work of Arts et Métiers ParisTech researchers and makes it freely available over the web where possible.

This is an author-deposited version published in: http://sam.ensam.eu

Handle ID: .http://hdl.handle.net/10985/9695

\section{To cite this version :}

Gildas GUILLEMOT, Adrien VAN GORP, Thierry COOREVITS, Alain IOST - Estimation of the constitutive law by dual Small Punch Test and Instrumented Indentation - Solid State Phenomena - Vol. 188, nAdvanced Materials and Structures IV, p.193-198 - 2012 


\title{
Estimation of the constitutive law by dual Small Punch Test and Instrumented Indentation
}

\author{
G. Guillemot ${ }^{1, a}$, A. Van Gorp ${ }^{1, b}$, T. Coorevits ${ }^{1, c}$, A. lost $^{1, d}$ \\ ${ }^{1}$ Arts et Métiers ParisTech, LML CNRS UMR 8107, 8, Boulevard Louis XIV 59000 Lille France \\ agildas.guillemot@ensam.eu, badrien.vangorp@ensam.eu, cthierry.coorevits@ensam.eu, \\ dalain.iost@ensam.eu
}

Keywords: Small Punch Test, instrumented indentation, inverse method, constitutive law

\begin{abstract}
In this paper an inverse finite element procedure was developed to assess the true- stress strain relationship of a DP dual phase. Experiments were performed both by means of instrumented indentation and small punch tests on small samples cut in the same steel sheet. Tests are developed on a Zwick macro-hardness tester. Single test are first proposed in order to estimate the parameters of the constitutive law $(K, n)$. We propose to conduct SPT tests using PTFE lubricant and hard (WC / Co) ball. An inverse method based on the Nelder and Mead algorithm has been developed in order to found experimental curves. Nevertheless we show that this method lead to poor estimation of the parameter of the constitutive law. We propose to improve these estimations by cross-mechanical tests. Indeed we show that the estimation of the low-error $(K, n)$ domains deduced from each single test can be crossed. This method leads to a better estimation of the constitutive law. Moreover both load/displacement curves of SPT and macrohardness can be found again.
\end{abstract}

\section{Introduction}

The Small Punch Test (SPT) was first developed to characterize the evolution of mechanical properties of materials for fusion power reactors under irradiation as a consequence of limited availability of specimen volume. This test is very useful in those situations where it is necessary to use small volumes of materials to characterize the mechanical properties and can be considered as a non-destructive test. Applications are performed in field where a characterization by means of conventional mechanical tests is impossible: nuclear or thermal plant equipments, coatings, heat affected zone of weld ... [1]. The mechanical properties determined by the SPT are the Fracture Appearance Transition Temperature (FATT), the fracture toughness $\left(K_{I C}, J_{I C}\right)$, the creep properties, and the plastic constitutive law. To determine this plastic constitutive law, indentation test may also be performed. With a ball indenter, the Automated Ball Indentation method from Haggag [2] presents the drawback to be empirical and for pointed indenter it was found that a single $P$ - $h$ curve optimization gives a non-uniqueness solution. Indeed more than one minimum vortex may be found meaning that the mechanical properties of the material cannot be uniquely decided by a single $P-h$ curve [3]. This non-uniqueness solution can be removed by the two $P-h$ curves optimization obtained for two conical indenters of different included angles [4], but this method is not precise since the include angles of the indenters are close to each other. For this reason, we propose to associate SPT and Vickers indentation to have a better estimation of the constitutive law. We present here some results obtained with the cross mechanical test approach developed on a DualPhase steel.

\section{Materials and methods}

The steel alloy used in order to develop the present cross-mechanical tests has been developed by the research centre of Arcelor-Mittal (site of Maizières-lès-Metz, Lorraine, France). This alloy is a dual-phase (DP) steel. Indeed, its microstructure is inhomogeneous. It is composed of two distinct phases: a soft ferrite phase $(85 \%)$ and a hard martensitic phase $(10 \%)$. Some residues of bainite phase are also observed (5\%). The mechanical strength, $R_{m}$, of this alloy is equal to $642 \pm 8 \mathrm{MPa}$. It 
will be designated as a 'DP' steel in this document. The ferrite-martensite DP steels are particularly used in the automotive industry field. Indeed they have a good drawability and a high hardness respectively due to the ferritic and martensitic domains.

The SPT test as it has been developed for the present study is a low deformation test applied on a thin sample of the DP alloy. Samples have disk geometry with a diameter of $8.9 \mathrm{~mm}$ and a thickness of $500 \mu \mathrm{m}$. The device is presented on Fig. 1-a. The ball diameter is equal to $2 \mathrm{~mm}$. It has been adapted in order to be installed on a Zwick macro-hardness tester ZHU 2.5. The apparatus is shown on Fig. 1-b. According to the manufacturer Zwick, this equipment allows to apply load from $5 \mathrm{~N}$ to $2500 \mathrm{~N}$ with an error lower than $1 \%$. The displacement is measured with a resolution of $40 \mathrm{~nm}$ on a range of $4 \mathrm{~mm}$ for the ball displacement. Ball displacement velocity is close to $0.5 \mathrm{~mm} . \mathrm{min}^{-1}$. Nevertheless, it should be mentioned that the mechanical behaviour of the DP alloy is few sensible to the deformation velocity. Balls are in Z $100 \mathrm{Cr} 17$ alloy or in carbide tungsten / cobalt (WC / Co) alloy. The high hardness of these materials enables to limit the ball deformation and its damage during the SPT.

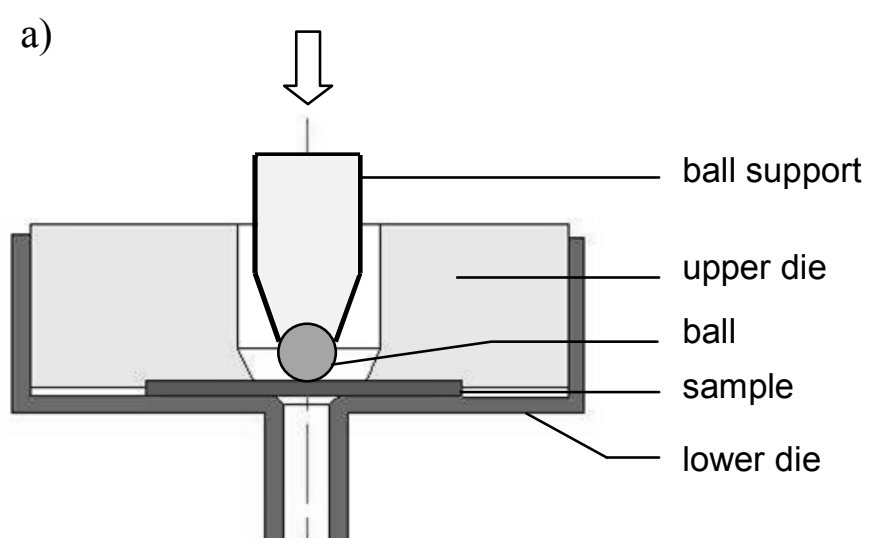

b)

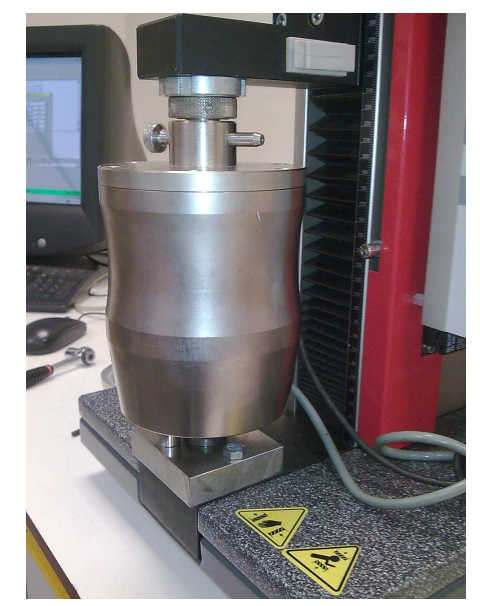

Fig. 1: a) Test device with the major components. b) Photograph of the testing apparatus Zwick ZHU 2.5. The device has been put under the load sensor.

We must mention that preliminary Brinell tests are conducted with the same equipment in order to test if the ball is correctly blocked into the support. Load-Displacement curves are used. The macrohardness tests have also been developed with the same Zwick equipment and a Vickers indenter in order to estimate load-displacement curves and compare both results.

SPT Samples are cut by spark-discharged machining from a $700 \mu \mathrm{m}$ thick DP steel sheet. The thickness of the final samples has to be greater than 10 times the grain size in order to obtain repeatability results. We have decided to work with sample of $500 \mu \mathrm{m}$ thickness. Grain size is close to $5 \mu \mathrm{m}$. Thus the previous condition is completely verified. This thickness is obtained by several consecutive polishing. During the various polishing, we have to verify that the opposite faces are still parallel.

A typical load displacement curve on a ductile alloy is shown in Fig. 2 a. This curve can be split in four domains corresponding to various mechanical behaviours:

Zone I - elastic bending: The load and the displacement into the sample linearly evolve. The deformation is localized in the contact between the sample and the ball.

Zone II - plastic bending: A transition in mechanical behaviour is observed. The sample is plastically deformed. The load increases slowly. The plastic domain increases both in the radial and normal directions.

Zone III - plastic stretching: generalized plastic deformation by stretching. The thickness of the sample decreases progressively. The contact area between the sample and the ball leads to an increase of the load. Some cracks appear at the surface of the sample. 
Zone IV - crack propagation: The slope of the curve quickly decreases. A maximum in the curve is shown and the load goes down. This phenomenon is due to a sharp decrease of the sample thickness and to the coalescence of the cracks.

a)

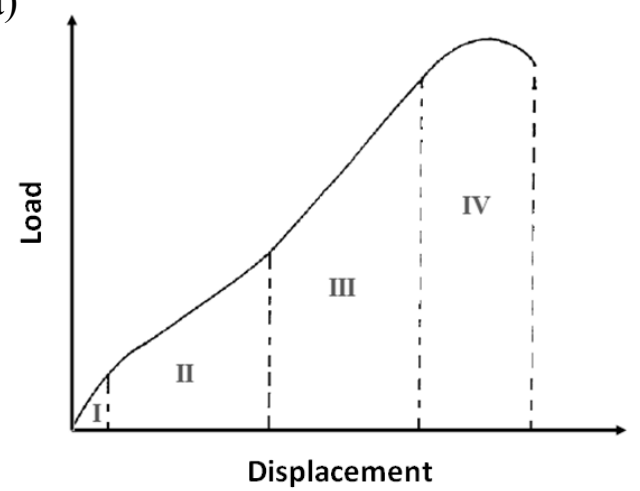

b)

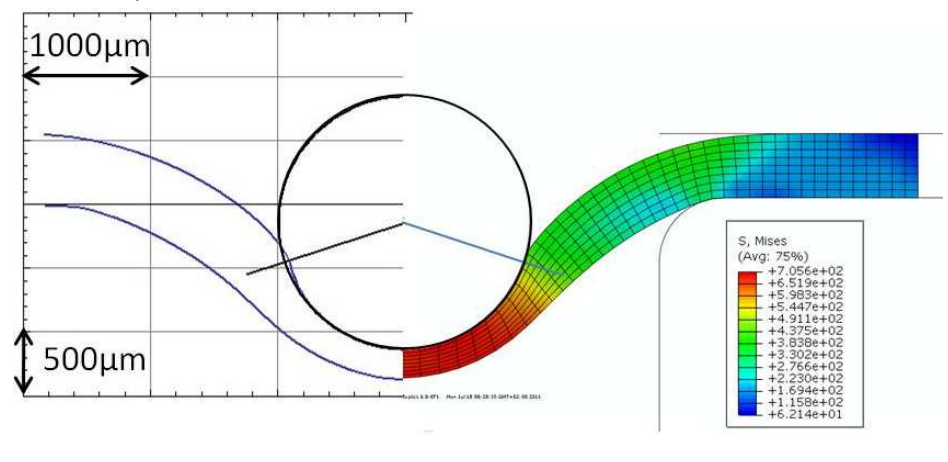

Fig. 2: a) Load/displacement curve obtained on ductile materials during a SPT test. b) Thickness evolution measured by Coordinate Measuring Machine (CMM) (left part) and the simulated geometry of the sample during loading (right part).

\section{Results and discussion}

In Fig.2.b a comparison between the profile section obtained by FEM analysis and measured by CMM shows a good correlation. Necking occurs near the side of the hemisphere and circumferential crack initiates at the necking section. The profile of cross section is very similar to the result of FEM analysis and the localized strain is largest around the necking area.

We developed SPT with a Z 100 Cr 17 grade steel or carbide tungsten / cobalt (WC / Co) alloy ball. Previously, a lubricant was deposited on the surface of the sample in order to decrease the friction forces. Lubricant oil (reference WD40) or PTFE (Polytétrafluoroéthylène or Teflon) polymer have been used. We must mention that the best results have been obtained with two tests, PTFE 1 and PTFE 2, conducted in the same condition (WC / Co ball and PTFE lubricant). Indeed these tests are quite similar and the scatter between them is quite small. Maximal measured load is $1404 \pm 26 \mathrm{~N}$. Previous test conducted with WD40 lubricant or Z $100 \mathrm{Cr} 17$ ball materials lead to larger scatter on SPT curves.

Macro hardness tests have been conducted on samples cut by spark-discharged machining in the original DP steel sheet. These new samples have been fixed with a hardening resin on the apparatus support. Indentations have been processed till $70 \mu \mathrm{m}$. This depth corresponds to $10 \%$ of the steel sheet thickness. The various tests conducted are similar. Maximal load is $213 \pm 6 \mathrm{~N}$. A 'median' test was between the others tests. We proposed to develop the cross tests approach with this latter one.

An inverse method has been developed in order to estimate the stress-strain curve parameters of the present DP alloy. We propose to use a power law relation for the description of the work hardening phenomenon. Thus considering a Hollomon relation, two parameters have to be estimated:

$$
\sigma=K \varepsilon_{p}^{n}
$$

$K$ corresponds to the strength index and $n$ to the strain hardening exponent. $\sigma$ and $\varepsilon_{p}$ are the true stress and plastic strain. The elastic deformation is given by the Lamé equation. Young modulus is equal to $201 \mathrm{GPa}$ and Poisson coefficient is equal to 0.3 . Thus only the parameters of the plastic stress-strain relation have been estimated. We estimated parameters from the stress-strain diagrams obtained for unidirectional tension test in various directions (longitudinally, with a $45^{\circ}$ angle and transversely) of the original DP steel sheet. The stress-strain curve is correctly estimated with parameters $K_{D P}=1091 \pm 10 \mathrm{MPa}$ and $n_{D P}=0.195 \pm 0.003$. We must mention that the mechanical properties are notably isotropic. 
Simulations of the mechanical tests have been conducted with the software Forge (Transvalor). A refinement of the mesh has been used in the sample / ball or sample / indenter contact domain. 1450 nodes have been used for the SPT simulation and 1040 nodes for the Vickers macrohardness simulation. It must be noticed that no cracks initiation has been simulated.

For the SPT test, the edges of the sample have been fixed with both upper and lower dies (Fig. 1). It has been shown in previous simulations that contact conditions between the sample and the dies have a low influence on the load - displacement curve. Indeed, the edges of the samples are fixed and immovable between the two dies. Thus we finally used a sliding condition between the sample and the die for all the simulations. This condition should correspond also to the use of a PTFE lubricant. For macrohardness Vickers test, we simplified the test and we considered an equivalent test with a conical indenter. We replaced in the simulation the Vickers indenter with an apical angle of $136^{\circ}$ by a conical one with a half-angle at the tip of $70.3^{\circ}$. Consequently, the projected areas of both indenters are the same for the same indentation depth. The results obtained with this hypothesis are similar to the ones obtained with the true Vickers hardness indenter [5].

For each simulation conducted with Forge for a given couple $(K, n)$, an error function, $F(K, n)$, is defined as the sum of the differences between the experiment and the simulation. This function is minimized step by step in order to estimate the best couple giving the true parameter of the Hollomon law. The Nelder and Mead algorithm [6] is proposed in order to find the best agreement between simulations and experiments.

Fig. 3 a) shows an example of the simplexes path calculated for a SPT conducted with the WD40 lubricant and a Z $100 \mathrm{Cr} 17$ grade steel ball. The initial simplex is first defined. Coordinates of the vertices of the other simplexes are then calculated step by step while the simplex is not reduced to a point. Its coordinates $\left(K_{f}=1340 \mathrm{MPa}\right.$ and $\left.n_{f}=0.247\right)$ correspond to the Hollomon law parameters leading to the best fit compare to the experimental results (Fig. $3 \mathrm{~b}$ ). Moreover we have developed a complete cartography of the function $F(K, n)$ on the range $\{K \in[800: 1500], n \in[0.1: 0.5]\}$. Contour lines can be shown on Fig. 3 a). As it was expected, they surround the dot $\left(K_{f}, n_{f}\right)$ corresponding to the minimization of the error function $F$. The simplex path has converged toward this couple. The results are respectively equal to 1267 and $1244 \mathrm{MPa}$ for $K$, and 0.28 and 0.29 for $n$ for the samples PTFE1 and PTFE2.

a)

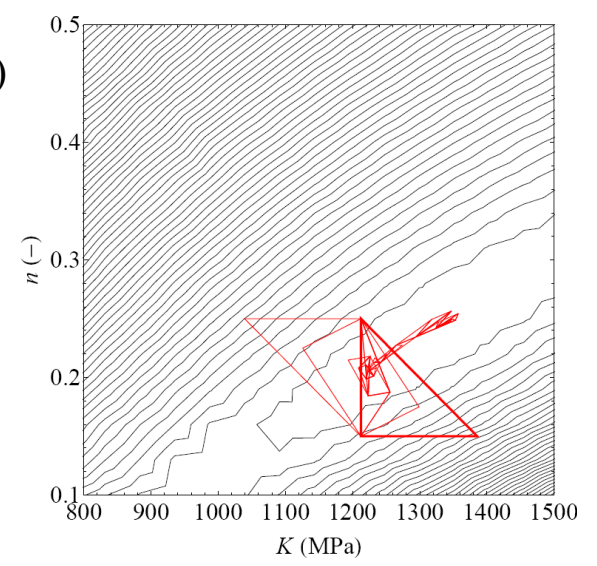

b)

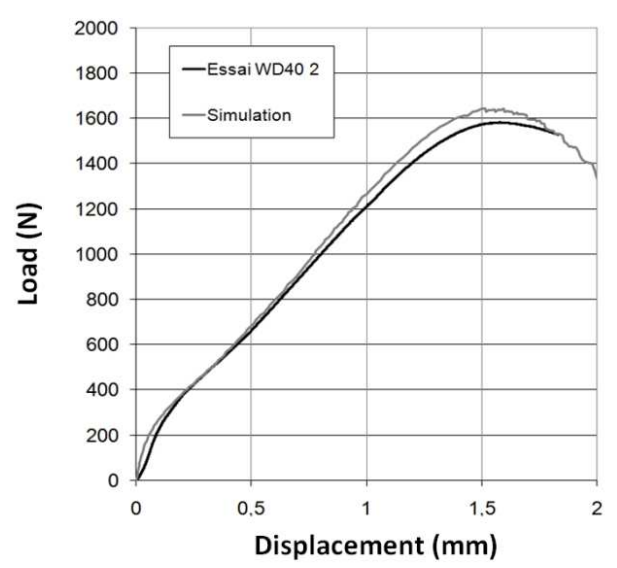

Fig. 3: a) Path of the simplexes (Nelder and Mead algorithm) obtained for a SPT test conducted with a WD40 lubricant oil. The isovalue lines for the error function $F$ are shown. The red bold lines triangle corresponds to the first simplex. b) Comparison of experimental and simulated curves for the couple $\left(K_{f}, n_{f}\right)\left(K_{f}=1340 \mathrm{MPa}\right.$ and $\left.n_{f}=0.247\right)$ obtained with the inverse method.

The previous approach has also been developed on macrohardness Vickers tests. Compare to SPT test, they are very repeatable. Thus it is not necessary to develop inverse method on various curves compare to SPT. The inverse approach has been developed on the 'median' test. Fig. 4-a shows the results of this method. The contour lines of the error function, $F(K, n)$ are also shown. The path of 
the simplexes also converged on the minimum value of the function $F$. The final simplex has been estimated to $\left(K_{f}=1100 \mathrm{MPa} ; n_{f}=0.227\right)$. A good result is also obtained when we compare experimental 'median' curve and simulated curve (Fig. 4 b).

a)

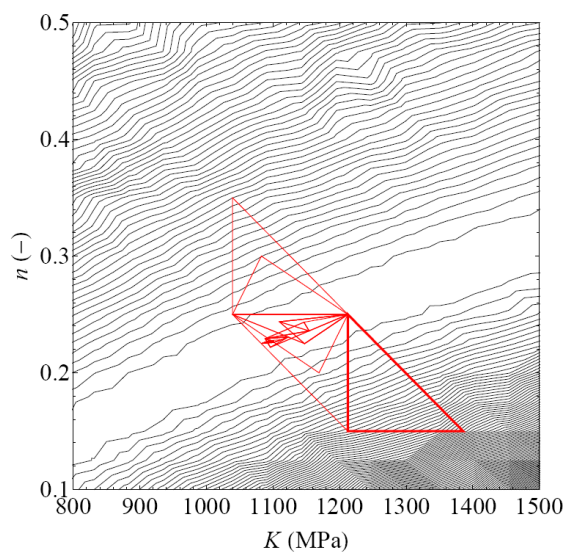

b)

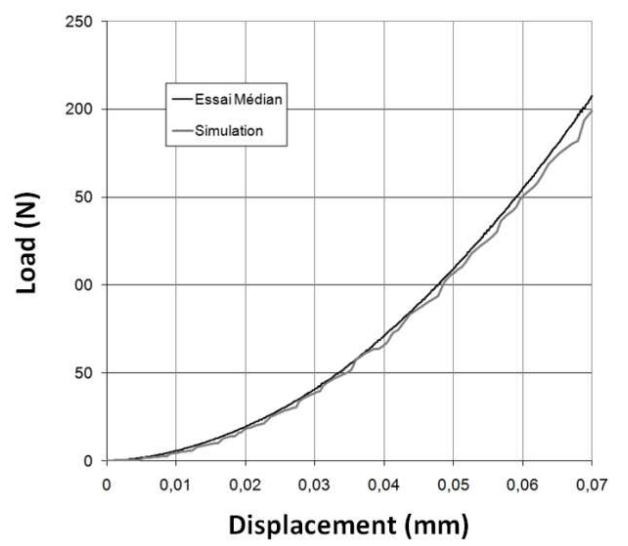

Fig.4: a) Path of simplexes for the median Vickers hardness test and isovalue lines of the error function, $F$. b) Comparison of experimental and simulated curves for the couple $\left(K_{f}, n_{f}\right)$ $\left(K_{f}=1100 \mathrm{MPa}\right.$ and $\left.n_{f}=0.227\right)$ obtained with the inverse method.

The previous approaches clearly show the difficulty to estimate the parameters of the DP steel for single inverse method. We do not find the true parameters only using SPT test. Some differences are still shown between estimated parameter on PTFE 1 and PTFE 2 tests and measurements. Differences are also observed for macrohardness test. These differences may be explained by the nonuniqueness of the solution as shown by [4]. Indeed, it could be expected that the friction force may be significant for both mechanical test and experimental load may be greater than simulated one's. Therefore, a sliding contact may be not relevant. SPT with PTFE (PTFE 1 and PTFE 2) lubricant leads to an overestimation of the strain hardening exponent, $n$, of $50 \%$. The macrohardness tests give a better estimation of strength index, $K$ (error lower than $1 \%$ ). Nevertheless, the strain hardening exponent is still overestimated (error close to $20 \%$ ).

These differences may be explained by the difficulty to estimate the minimum error function and both parameters with a single mechanical test [7]. As presented on the contour lines on Fig. 3 a) and 4 a), the error function $F(K, n)$ slowly evolves in one of the directions. Thus, simplex method can lead to small values (i.e. local minimum) of the error function for couples $(K, n)$ that do not correspond to the correct minimization of the error function (i.e. global minimum). The experimental SPT or macrohardness curve is then correctly found but the result can be improved. Moreover the hardening behaviour of the DP steel which may not be completely described by a power relation (Hollomon relation) and scatter in experimental results may also lead to the development of local minimums. For these reasons, the simplex method may not always give the best estimation of parameters. These also explain the scatter shown in the estimation of these parameters. Consequently a single SPT or macrohardness test is not a relevant method to estimate both parameters.

In order to estimate the true parameters, the method we proposed consists to cross the contour lines cartography (Fig. $5 \mathrm{a}$ and $5 \mathrm{~b}$ ). These contour lines enable to estimate the minimum evolution direction (dotted lines) of the error function, $F$. In this direction, the experimental function estimation is good. The two lines cross each other in a point, $(K, n)$, corresponding to a correct estimation of the 'true' couple. Indeed, this couple enable to obtain correct simulation of both the SPT and macrohardness curves. It can be considered as a better estimation than the couple estimated with a single test and an inverse method (Figs. 3, 4). The results are respectively equal to 1174 and $1001 \mathrm{MPa}$ for $K$, and 0.24 and 0.19 for $n$ for the samples PTFE1 and PTFE2. These values are clearly closer to the true parameter than the ones previously presented for the single SPT tests. 
a)

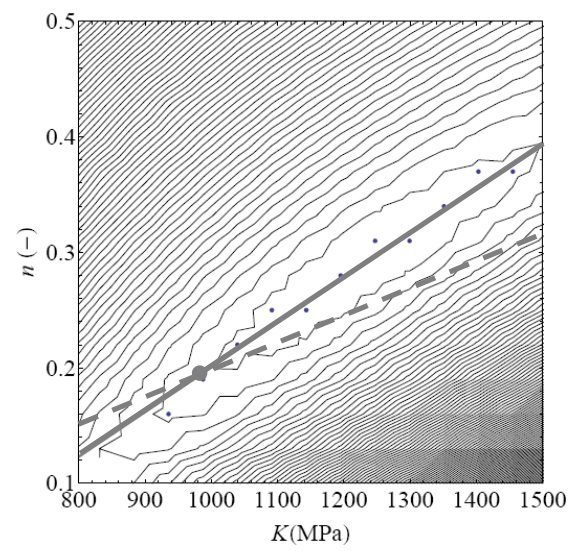

b)

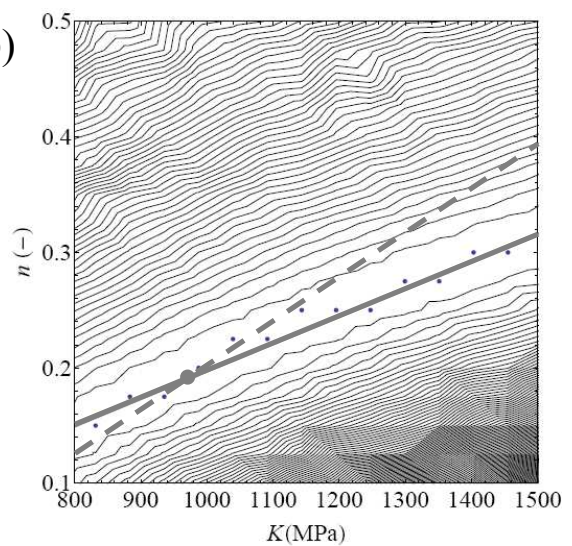

Fig. 5: Minimum error function lines (grey lines) for a small punch test experiment (a) and the Vickers hardness test (b). Dots correspond to the minimum values of error function $F$ where the regression is done.

\section{Conclusion}

The present investigation deals with the determination of the constitutive law of DP steel widely used in the automotive industry by small punch test and instrumented indentation. The following conclusions can be therefore drawn:

- The use of a lubricant decreases the friction force and reduces the experimental dispersion in SPT results. The use of hard ball in WC-Co alloy is also recommended.

- A common inverse approach has been proposed in order to estimate the constitutive law of a DP steel. Nevertheless some differences are shown between estimated and true parameters of this law.

- Improvement in constitutive law parameter estimation is made by coupling the results of the objective function of the small punch test together with those of the indentation curve. The maximum prediction relative errors for $K$ and $n$ are less than $10 \%$.

- Some improvements should to be done in this approach, considering a new constitutive law, other mechanical tests or measurements on the final sample geometry.

\section{Acknowledgments}

The authors thank Mrs. G. Starzyk, F. Baratto, N. Charoy and M. Moura for the projects they realised to develop the SPT equipment and to realize the tests presented here. Moreover we thank Drs. S. Allain and J.-Ph. Masse (ArcelorMittal, Maizières-lès-Metz) for the DP steel sheets supplied and discussions on the DP characterization. We also thank J.C. Vervisch for its valuable help in experimental activities.

\section{References}

[1] $1^{\text {st }}$ International Conference on SSTT, Determination of Mechanical Properties of Materials by Small Punch and other Miniature Testing Techniques, Ostrava Czech Republic, 2010

[2] F.M. Haggag, "Field Indentation Microprobe for Structural Integrity Evaluation," U.S. Patent No.4,852,397, August 1, 1989, foreign patents pending.

[3] X. Chen, N. Ogasawara, M. Zhao, N. Chiba, J Mech Phys Solids, Vol. 55 (2007), p.1618.

[4] J. Luo, J. Lin, Int. J. of Sol. and Struc., Vol. 44 (2007), p. 5803

[5] M. Dao, N. Chollacoop, K.J. Van Vliet, T.A. Venkatesh, S. Suresh, Acta Mater. Vol. 49 (2001), p. 3899

[6] J. A. Nelder, R. Mead, Computer Journal, Vol. 7 (1965), p. 308

[7] J. Isselin, A. Iost J. Golek, D. Najjar, M. Bigerelle, J. Nucl. Mat., Vol. 352, Is. 1-3(2006), p. 97 
